Int. J. Electrochem. Sci., 12 (2017) $4044-4055$

\title{
The Electrochemical Corrosion Properties of PANI/Coal Composites on Magnesium Alloys
}

\author{
Yan Wang ${ }^{1,2, *}$, Jun Wang $^{2,3}$ and Xiaofei Zhang ${ }^{4}$ \\ ${ }^{1}$ Research Center for Engineering Technology of Polymeric Composites of Shanxi Province, North \\ University of China, Taiyuan 030051, People's Republic of China \\ ${ }^{2}$ School of Materials Science and Engineering, North University of China, Taiyuan 030051, People's \\ Republic of China \\ ${ }^{3}$ Technology Center, Shanxi Taigang Stainless Steel Co., Ltd., Taiyuan 030003, People's Republic of \\ China \\ ${ }^{4}$ School of Mechanical and Power Engineering, North University of China, Taiyuan 030051, People's \\ Republic of China \\ *E-mail: wangyan224@nuc.edu.cn
}

doi: $10.20964 / 2017.05 .81$

Received: 23 January 2017 / Accepted: 19 March 2017 / Published: 12 April 2017

\begin{abstract}
A study on the corrosion protection properties of PANI/Coal composites is presented. PANI/Coal composites were synthesized by in situ polymerization, and coatings containing epoxy and PANI/Coal composites were prepared on the surface of magnesium alloys. The structure, morphology and properties of the samples were characterized using Fourier transformation infrared (FTIR) spectroscopy, scanning electron microscopy (SEM), and electrochemical impedance spectroscopy (EIS). The FT-IR spectra showed that the acid-doped PANI/Coal composites were successfully synthesized, and the SEM images indicated that the samples had nanorod structures. The EIS results revealed that the corrosion current density and corrosion rate of the PANI/Coal composite coatings decreased by $2 \sim 3$ orders of magnitude compared to the pure magnesium alloy. The impedance of the PANI/Coal composites at low frequencies was enhanced with the increasing coal content. The results indicated that PANI/Coal composites could prominently improve the corrosion protection properties of magnesium alloys. The protective mechanisms of the PANI/Coal composites are also discussed. The excellent anticorrosive properties can expand the applications of magnesium alloys in harsh environments.
\end{abstract}

Keywords: PANI/Coal composites, Corrosion, EIS, Magnesium Alloy

$\underline{\text { FULL TEXT }}$ 
(C) 2017 The Authors. Published by ESG (www.electrochemsci.org). This article is an open access article distributed under the terms and conditions of the Creative Commons Attribution license (http://creativecommons.org/licenses/by/4.0/). 